\title{
Understanding and Thinking of College Mathematical Modeling and Experiment Course Construction
}

\author{
Zhaohai WANG \\ Department of mathematics and statistics, Ankang University, Ankang, Shanxi, 725000, China \\ akwzh@163.com
}

\begin{abstract}
Mathematical modeling and experiment is the product of the times. It can effectively promote the development of teaching reform and the cultivation of talents. In this paper, the writer gives some viewpoints on the status and function of developing the mathematical modeling and mathematical experiment in colleges and universities, as well as on the approaches to the course construction.
\end{abstract}

Index Terms - mathematical modeling, mathematical experiment, course construction

\section{Introduction}

In recent years, many colleges and universities have targeted the development of application-oriented undergraduate education. The goal is to train the talents who could solve practical problems at the forefront of production. The aim of learning mathematics for the talents in undergraduate education is to apply theory to practice; it requires the talents to improve the consciousness of using mathematics, interest and ability continuously. Mathematical modeling and mathematical experiment is the best combining site of improving the knowledge and application ability of mathematics. It is the best approach of inspiring creative consciousness and creative thinking, improving creativity, and cultivating applied talents in undergraduate education.

\section{The Status and Function of the Mathematical Modeling and Mathematical Experiment}

\subsection{Mathematical modeling and mathematical experiment is the need of the development of the times}

In the era of knowledge economy, the status of Mathematics has been greatly changed. Under the influence of economic globalization, the rapid development of computer technology, and the expansion of mathematic theories and techniques, the application of mathematics is more and more deep and wider. It is being applied not only in the field of natural science, and has penetrated into the areas of military, economic, social and human sciences, and many new subjects come into being in the process of application. The status and function of mathematic application in the high-tech field is increasingly prominent. It has become an important part of modern hightech and think tank, also become the important pillar of technology development. Math has become a universal application of technology. Practical problems, which should be solved urgently, exist in all fields, but practical issues tend to be complex and ever-changing, and the relationship between the quantity and quantity is not obvious, so they can not be brought to satisfactory settlements. It requires that the practitioners have higher mathematical attainment, which means strong abstract skills, induction and logical thinking ability, they should be able to identify the common and natural things among numerous issues, be good at grasping the principal contradiction, finding the regular pattern from countless data and quantitative analyses, using mathematics knowledge and mathematical thinking method to solve practical issues, so as to achieve the purpose of serving the society. In those applications, mathematical modeling, as the bridge of connecting the mathematical theories and practical problems, is indispensible. Seeking the inherent characteristics and inherent laws by collecting data purposively, grasping the principal contradiction by abstracting and simplifying, so as to build the mathematical modeling to reflect the quantitative relation in practical problems, then using mathematical approaches and skills to analyze and solve them.

Mathematics experiment is a new experimental teaching mode in recent years; it is based on the mathematical theory and practical problems. It takes advantage of modern teaching methods and mathematic software; combines the theories, practical problems and computers through computer simulation and numerical calculation, so as to let the students grasp the way of using mathematic software and the basic modeling method. It cultivates the integrated skills of analyzing and solving problems. So it's necessary to set this course in colleges and universities.

\subsection{Mathematical modeling and mathematical experiment is the need of cultivating the students' innovative consciousness and innovative ability}

Mathematics is a new basic science. People have regarded mathematics as a basic tool for non Mathematics Major for a long time, thus mathematics teaching just focus on imparting knowledge, this understanding is one-sided. Mathematics is not just the language and essential tool of modern science and technology, but a rational mode of thinking. Good mathematical literacy is not only an important part of the scientific and cultural qualities of talents of high quality, but also the foundation of innovation. From learning book knowledge to applying knowledge to solve practical problems often has a certain distance. For students of engineering and management, in particular, the abstract skills of promoting a real problem to a mathematical model should be the basic qualifications, which must be learnt through practice, not from books. The knowledge and experience learnt through practice 
are more likely to be internalized as people's quality. Besides, the cultivation of innovative consciousness and innovative ability is the important connotation of quality education. Mathematical modeling and mathematical experiment course combine the teaching and experiments that can help to train students' innovation consciousness and innovation capacity.

\subsection{Mathematical modeling and mathematical experiment is the needs of education reform}

The educational concept in higher education should be changed from professional education to quality education, from exam-oriented education to ability education, from teaching to learning, and from formalization to instantiation. Teachers should guide students to participate and explore actively rather than accept passively, should gradually reduce the classroom teaching time, increase extracurricular selfstudy time; should bring researches into the teaching process, so as to make the teaching scientific; should protect and encourage students' every little bit of innovation consciousness. [1]In the aspect of the teaching contents and teaching system, teachers should improve the ability of rational thought, cultivate the integrated skills of problem identifying and solving.

Mathematical modeling and mathematical experiment is the most representative course, it includes numerical analysis, statistical calculation, the basic definition and methods of optimized calculation, aiming for improving the students' ability of mathematical modeling, algorithm design and data processing.[2] The traditional course of higher mathematics, including calculus, linear algebra, probability and statistics, focus on knowledge learning, but the whole teaching process is lack of practical sessions, thus the students can neither fully understand and grasp the theories, nor solve the practical problems by using the knowledge they've learnt in the class. As one of the public basic courses, the study period of mathematics is generally shorter than others, so it's impossible for the teachers to spend much time on further discussion of the solution to the practical problems. Meanwhile, most of the practical problems can be solved by using multidisciplinary knowledge comprehensively. Mathematical modeling and mathematical experiment course remedy these deficiencies effectively; it plays an important role in undergraduate practical teaching and teaching reform of engineering mathematics.[4]

\section{The Approaches to the Course Construction of Mathematical Modeling and Mathematical Experiment in Colleges}

\subsection{Organize a high-quality team of teachers}

Teachers are the dominant force in the process of teaching practice, are the foundation of the course construction. Without a good teaching team, there's no high-quality teaching effect. Mathematical modeling and mathematics experiment course has higher requirements for teachers, which means the teachers should have high theoretical attainments and application ability. So it's crucial to stick to combine teaching with scientific research and form a team of teachers with high professional quality.

\subsection{Reform the teaching contents, lay stress on the practicability of the course}

The reform of teaching content is the key of mathematical modeling and mathematical experiment course construction; it runs through the whole process of curriculum construction. The main purpose of this course is cultivating the students' application ability. Therefore, in the process of organizing teaching contents, teachers shouldn't emphasize the system and rigor of mathematics too much, but emphasize the conversion from practical problem to mathematical modeling, and the ability of realizing this conversion.[3] Promoting "problems" teaching consciousness, so that students can come into contact with researches earlier, find out problems, and then create something, achieve the ultimate goal, the exploratory learning. Through the repeated training of the modeling process of various different practical problems, students can improve the ability of building models while deepen the understanding of the mathematical theory.

\subsection{Reform the teaching approaches, complete construction of network teaching}

Teachers should take full advantage of modern technology to enrich the teaching approaches, and build the online course of mathematical modeling and mathematics experiment. Online course can realize the combination of documents, video, audio, flash, and mathematical application software, greatly enrich the expression of teaching contents.[4] As the supplement to class teaching, it facilitates the students ' independent learning. Meanwhile, a mathematical modeling website should be established, which provide students good environment of study, discussion and communion, it also offers a more convenient channel for communication between teachers and students.

\subsection{Reform teaching methods; highlight the practicality of the course}

The core of practice is to develop the individual subjective initiative, and then take the initiative into understanding and changing the world. The practice is the most vivid and useful textbook. In traditional teaching mode, the tendency of emphasizing on theory does exist, so the practicality should be protruded in the course reform. Adopting the mode of "case teaching", let the students' keep an independent and groping study pattern. Always to strengthen the students' participation and strengthen the practical training, cultivate the spirit of exploration, and focus on the cultivation of students' practical ability and practical ability.[6]

\subsection{Combine with science and technology competition; expand the space of the course}

It's crucial to combine the class teaching with the activities of teaching and research base for innovative practices; to organize students to participate in national and 
international undergraduate mathematical modeling contest, and to organize seminar report, interest groups, competitions and training activities, in order to expand the classroom to a broader space, so that more and more students can gain a deeper and lasting training of modeling capability.[7]

\subsection{Develop teaching innovation; focus on infiltrating mathematical modeling into the teaching of all subjects}

Mathematical education in engineering courses should focus on strengthening the relationship with practice and other subjects. Many subjects are based on mathematics, and have close relation with it, so it's easy and effective to infiltrate mathematical modeling into them, and to achieve the aim of developing the education of mathematical modeling widely and continuously.

\section{References}

[1] Qin Xuanyun, etc. To the understanding of the mathematical experiment course teaching and the teaching process implementation method. Journal of engineering mathematics, 2002, 18 (6): 44-45.

[2] LengJinSong, etc. The content of the mathematical experiment course setup and selection. Journal of engineering mathematics, 2001, 17 (2): 57-59.

[3] Liu Bangji. Mathematics experiment method and its philosophical thinking. Science, technology and dialectics, 1994, (3): 5-11.

[4] ChengZhongPing Wang Xiaohui. What is the mathematical experiment. Journal of higher education science, 2001, (2): 24 to 28.

[5] Zhang Xiaolei Guo Huaguang. Try to talk about mathematics education function of mathematical experiment. Journal of mathematics education, 2003, 12 (2) 38

[6] SuiMing $\mathrm{Xu}$ Minhui. Mathematics experiment and mathematics teaching. Journal of mathematics education, 2004, 13 (2): 93.

[7] Yao Zhigang. military colleges and universities of the exploration and research of laboratory construction of disciplines. Journal of experimental technology and management, 2006, 23 (5): 136-139. 